\title{
CXCR4 blockade sensitizes osteosarcoma to doxorubicin by inducing autophagic cell death via PI3K-Akt-mTOR pathway inhibition
}

\author{
YU-XIN LIAO ${ }^{1}$, JI-YANG LV ${ }^{2}$, ZI-FEI ZHOU ${ }^{1}$, TIAN-YANG XU ${ }^{1}$, DONG YANG ${ }^{1}$, \\ QIU-MING GAO $^{1}$, LIN FAN ${ }^{1}$, GUO-DONG LI ${ }^{1}$, HAI-YANG YU ${ }^{1}$ and KAI-YUAN LIU ${ }^{1}$
}

\begin{abstract}
${ }^{1}$ Department of Orthopaedics, Shanghai Tenth People's Hospital, Tongji University School of Medicine, Shanghai 200072;
${ }^{2}$ State Key Laboratory of Microbial Metabolism, Sheng Yushou Center of Cell Biology and Immunology,

School of Life Science and Biotechnology, Shanghai Jiao Tong University, Shanghai 200240, P.R. China
\end{abstract}

Received January 21, 2021; Accepted May 10, 2021

DOI: 10.3892/ijo.2021.5229

\begin{abstract}
Doxorubicin is one of the most frequently used chemotherapy drugs in the treatment of osteosarcoma (OS), but the emergence of chemoresistance often leads to treatment failure. C-X-C motif chemokine receptor 4 (CXCR4) has been demonstrated to regulate OS progression and metastasis. However, whether CXCR4 is also involved in OS chemoresistance and its molecular mechanisms has yet to be fully elucidated. In the present study, CXCR4-mediated autophagy for OS chemotherapy was investigated by western blot analysis, transmission electron microscopy and confocal microscopy. CXCR4 silencing enhanced doxorubicin-induced apoptosis by reducing P-glycoprotein in CXCR4 ${ }^{+}$LM8 cells, while CXCR4 overexpression promoted OS doxorubicin resistance in CXCR4-Dunn cells. Furthermore, CXCR4 silencing with or without doxorubicin increased the expression of beclin 1 and light chain $3 \mathrm{~B}$, and the number of autophagosomes and autolysosomes, as well as induced autophagic flux activation by suppressing the PI3K/AKT/mTOR signaling pathway. In addition, pretreatment with the autophagy inhibitor bafilomycin A1 attenuated CXCR4 abrogation-induced cell death. Finally, the CXCR4 antagonist AMD3100 synergistically reinforced the antitumor effect of doxorubicin in an orthotopic OS mouse
\end{abstract}

Correspondence to: Dr Hai-Yang Yu or Dr Kai-Yuan Liu, Department of Orthopaedics, Shanghai Tenth People's Hospital, Tongji University School of Medicine, 301 Yanchang Road, Shanghai 200072, P.R. China

E-mail: yhybruce@163.com

E-mail: liuky2019@163.com

Abbreviations: OS, osteosarcoma; CXCR4, C-X-C motif chemokine receptor 4; CXCL12, C-X-C motif chemokine ligand 12; P-gp, P-glycoprotein; MDR1, multidrug resistance 1; HMGB1, high mobility group box 1; CA-4, combretastatin A-4; 3-MA, 3-methyladenine

Key words: osteosarcoma, doxorubicin, chemoresistance, CXCR4, autophagic cell death model. Taken together, the present study revealed that CXCR4 inhibition sensitizes OS to doxorubicin by inducing autophagic cell death. Therefore, targeting the CXCR4/autophagy axis may be a promising therapeutic strategy to overcome OS chemotherapy resistance.

\section{Introduction}

Osteosarcoma (OS) is the most frequent primary malignant bone tumor type, which predominantly affects children and adolescents, and accounts for approximately $15 \%$ of all bone malignancies $(1,2)$. The current standard clinical treatment for OS includes preoperative chemotherapy followed by surgical removal of the primary tumor, combined with postoperative chemotherapy. Since chemotherapy was introduced in the 1970s, the 5-year survival rate of OS has markedly improved from $<20$ to $70 \%$ (3). Doxorubicin, cisplatin and methotrexate are the most commonly used first-line chemotherapy drugs in the treatment of OS $(4,5)$. Despite great advances in chemotherapy for OS, the survival rate has reached a plateau and has remained unsatisfactory in the past three decades, largely due to chemotherapy resistance $(6,7)$. Among patients with OS, $>40 \%$ are not sensitive to chemotherapy drugs, and the 5 -year survival rate is only $16-20 \%$ (8). The emergence of chemoresistance often leads to treatment failure and poor prognosis, and has, therefore, become a major obstacle to improve OS therapeutic effect. Thus, it is imperative to elucidate the underlying molecular mechanisms involved in OS chemoresistance.

C-X-C motif chemokine receptor 4 (CXCR4) is a $\mathrm{G}$ protein-coupled receptor (GPCR) to which $\mathrm{C}-\mathrm{X}-\mathrm{C}$ motif chemokine ligand 12 (CXCL12) binds with high affinity (9). Accumulating evidence has indicated that CXCR4 plays a crucial role in OS progression and metastasis (10-12). In addition, CXCR4 has been shown to be associated with poor survival of patients with OS, and is considered an important clinical prognosis indicator (13). Increased attention has been paid to CXCR4-mediated chemotherapy resistance in various types of tumor (14-17). However, the association between CXCR4 and OS chemoresistance remains unknown. 
Autophagy is a catabolic process via which cells eliminate and recycle their own damaged proteins and organelles to provide energy. It has been demonstrated that autophagy plays a dual role in the regulation of OS resistance (18). While moderate autophagy can lead to drug resistance due to its cytoprotective effect, excessive autophagy reverses drug resistance by inducing cell death (18). Previous findings revealed that CXCR4 promoted OS growth and metastasis by activating the AKT signaling pathway (10). Since the PI3K/AKT/mTOR axis is one of the key regulators of autophagy, it was hypothesized that CXCR4 is involved in OS resistance to doxorubicin by regulating autophagy.

The aim of the present study was to investigate whether CXCR4 blockade could enhance the sensitivity of OS to doxorubicin by inducing autophagic cell death and whether CXCR4 is a potential therapeutic target to reverse OS doxorubicin resistance.

\section{Materials and methods}

Cell lines and culture. The murine LM8 and Dunn OS cell lines were kindly donated by Dr Eugenie Kleinerman (MD Anderson Cancer Center, University of Texas, Houston, TX, USA). The cell lines were cultured in high-glucose DMEM (Thermo Fisher Scientific, Inc.) supplemented with 10\% FBS (Gibco), $100 \mathrm{U} / \mathrm{ml}$ penicillin and $100 \mu \mathrm{g} / \mathrm{ml}$ streptomycin. The cultures were incubated at $37^{\circ} \mathrm{C}$ in a humidified atmosphere containing $5 \% \mathrm{CO}_{2}$.

Reagents and antibodies. Doxorubicin (cat. no. S1208), rapamycin (cat. no. S1039), bafilomycin A1 (cat. no. S1413) and AMD3100 (cat. no. S8030) were purchased from Selleck Chemicals. Antibodies against CXCR4 (cat. no. ab124824), PI3K (cat. no. ab40776), mTOR (cat. no. ab134903) and phosphorylated (p)-mTOR (cat. no. ab109268) were purchased from Abcam. Antibodies against beclin 1 (cat. no. 3738S), light chain 3B (LC3B; cat. no. 12741S), cleaved-caspase 3 (cat. no. 9664S), p-PI3K (cat. no. 4228S), AKT (cat. no. 4685S), p-AKT (cat. no. 4060S) and GAPDH (cat. no. 5174S) were purchased from Cell Signaling Technology, Inc. Anti-P-glycoprotein antibody (P-gp; cat. no. 49042) was purchased from Signalway Antibody LLC, while anti-caspase 3 antibody (cat. no. 19677-1-AP) was purchased from ProteinTech Group, Inc.

Cell viability assay. LM8 and Dunn cells $\left(2 \times 10^{4}\right.$ cells $\left./ \mathrm{ml}\right)$ were seeded in 96 -well plates overnight at $37^{\circ} \mathrm{C}$ and then treated with various concentrations of doxorubicin $(0,0.2,0.4,0.8,1$ and $10 \mu \mathrm{g} / \mathrm{ml})$. A concentration of $0.2 \mu \mathrm{g} / \mathrm{ml}$ was equivalent to $344.84 \mathrm{nM}$. After $48 \mathrm{~h}$ of incubation at $37^{\circ} \mathrm{C}, 10 \mu \mathrm{lCell}$ Counting Kit-8 (CCK-8) solution (Dojindo Molecular Technologies, Inc.) was added to each well for $1 \mathrm{~h}$ at $37^{\circ} \mathrm{C}$. The optical density (OD) was then measured using a microplate reader (EL800; BioTek Instruments, Inc.) at $450 \mathrm{~nm}$. The cell viability was calculated using the equation: Cell viability $(\%)=\left(\mathrm{OD}_{450 \mathrm{~nm}}\right.$ of treatment $/ \mathrm{OD}_{450 \mathrm{~nm}}$ of control) $\times 100 \%$. The $\mathrm{IC}_{50}$ was calculated by GraphPad Prism 8.0 (GraphPad Software, Inc.).

Plasmid and small interfering RNA (siRNA) transfection. Transfection was performed using Lipofectamine ${ }^{\circledR} 2000$ transfection reagent (Thermo Fisher Scientific) according to the manufacturer's protocol. LM8 and Dunn cells were transfected with $100 \mathrm{nM}$ mouse siCXCR4 (5'-GCAUAGUCG GCAAUGGAUUTT-3') (Shanghai GenePharma Co., Ltd.) and $1 \mu \mathrm{g} / \mathrm{ml}$ plasmids encoding CXCR4 (Shanghai GenePharma Co., Ltd.). A scrambled siRNA used as the negative controls (5'-UUCUCCGAACGUGUCACGUTT-3'). Both LM8 and Dunn cells were transfected with mRFP-GFP-LC3 adenovirus (Asia-Vector Biotechnology) or adenovirus vector containing RFP and GFP (Asia-Vector Biotechnology) as control. Transfection efficiency was assessed by western blotting.

Flow cytometry. LM8 and Dunn cells $\left(5 \times 10^{4}\right.$ cells $\left./ \mathrm{ml}\right)$ were cultured in 6-well plates for $24 \mathrm{~h}$ and treated with $0.2 \mu \mathrm{g} / \mathrm{ml}$ doxorubicin, or with siCXCR4/CXCR4 overexpression, or with $0.2 \mu \mathrm{g} / \mathrm{ml}$ doxorubicin combined with siCXCR4/CXCR4 overexpression. After $48 \mathrm{~h}$ of incubation, cell apoptosis was evaluated using an Annexin V-FITC apoptosis detection kit (BD Biosciences), and was detected by flow cytometry (FC500; Beckman Coulter). The cell apoptosis rate was calculated and analyzed with FlowJo software (version: V10.5.2, Becton, Dickinson and Company).

Western blotting. Total protein was extracted from cells using RIPA lysis buffer (cat. no. P0013B, Beyotime Institute of Biotechnology) containing phosphatase inhibitors, and was quantified with a BCA protein assay kit (Beyotime Institute of Biotechnology). Equivalent quantities of protein (40 $\mu \mathrm{g} / \mathrm{lane})$ were separated by $10-12 \%$ SDS-PAGE at $80 \mathrm{~V}$ for $1.5 \mathrm{~h}$ and transferred to polyvinylidene difluoride membranes. After blocking with TBS-0.05\% Tween 20 (TBST) containing 5\% skimmed milk for $1 \mathrm{~h}$ at room temperature, the membranes were incubated overnight at $4{ }^{\circ} \mathrm{C}$ with primary antibodies against CXCR4, beclin 1, LC3B, P-gp, cleaved caspase 3, caspase 3, p-PI3K, PI3K, p-AKT, AKT, p-mTOR and mTOR (all diluted 1:1,000). The membranes were rinsed with TBST three times and subsequently incubated with Anti-rabbit IgG, HRP-linked Antibody (cat. no. 7074, Cell Signaling Technology, 1:1,000 dilution) for $1 \mathrm{~h}$ at room temperature. The protein bands were then visualized using an ECL kit (cat. no. P0018S, Beyotime Institute of Biotechnology). Semi-quantitative analysis of proteins was performed with Image $\mathbf{J}$ software (National Institutes of Health, version 1.8.0).

Confocal microscopy analysis. LM8 and Dunn cells were cultured at $37^{\circ} \mathrm{C}$ in 6 -well plates and transfected with mouse CXCR4 siRNA or CXCR4-encoding plasmids using Lipofectamine 2000 (Thermo Fisher Scientific) according to the manufacturer's transfections for $48 \mathrm{~h}$. Next, cells were simultaneously treated with $0.2 \mu \mathrm{g} / \mathrm{ml}$ doxorubicin and mRFP-GFP-LC3 adenovirus for $48 \mathrm{~h}$. Subsequently, the cells were fixed with $4 \%$ formaldehyde for $30 \mathrm{~min}$ and incubated with DAPI for $5 \mathrm{~min}$. Images were obtained using a confocal laser scanning microscope (Olympus Corporation) (magnification, $\mathrm{x} 400$ ).

Transmission electron microscopy. LM8 and Dunn cells $\left(1 \times 10^{6}\right)$ were fixed with $2.5 \%$ glutaraldehyde at $4^{\circ} \mathrm{C}$ overnight and then fixed in $1 \%$ buffered osmium tetroxide at room temperature for $1.5 \mathrm{~h}$. Next, the cells were dehydrated with increasing concentrations of ethanol $(25,50,70,90$ and $100 \%)$ 

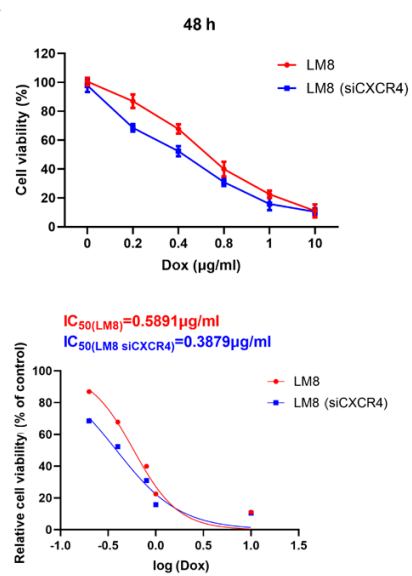
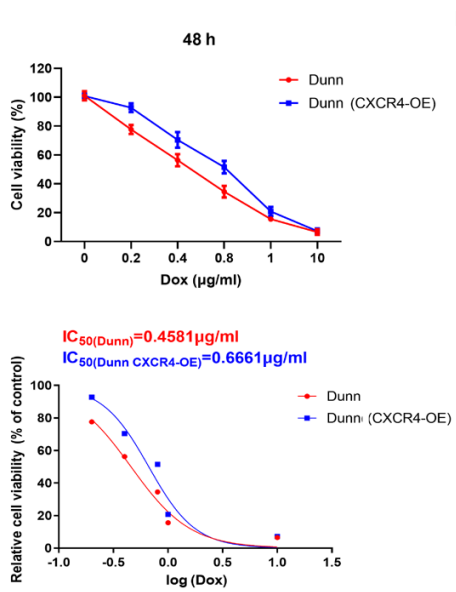

B
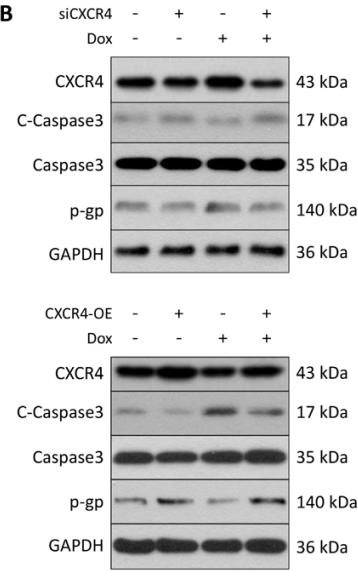
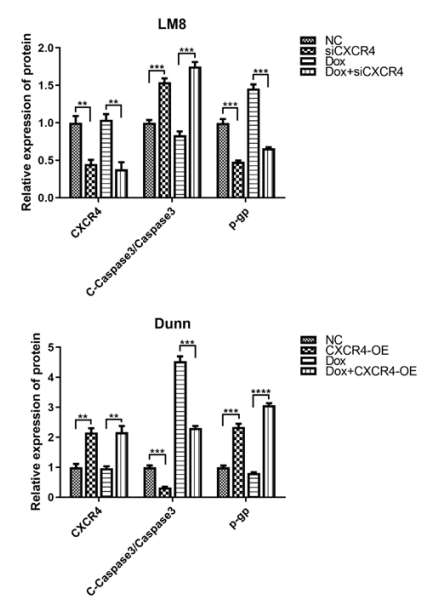

C
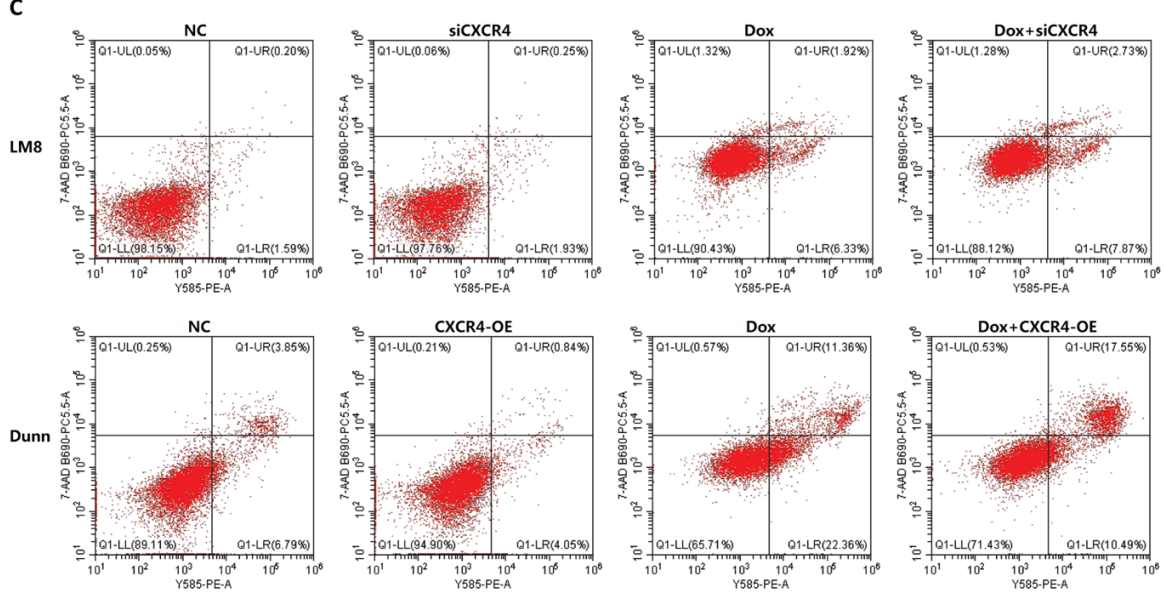
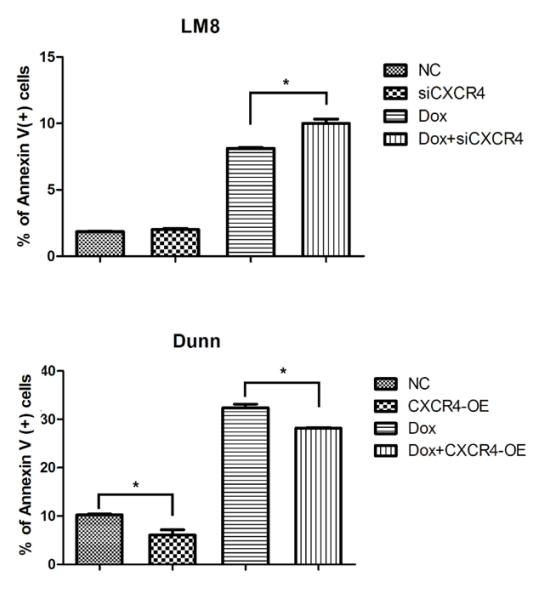

Figure 1. CXCR4 is implicated in the regulation of osteosarcoma doxorubicin resistance. (A) CXCR4 was downregulated in CXCR4-positive LM8 cells by small interfering RNA and upregulated in CXCR4-negative Dunn cells by lentiviral transfection. LM8 and Dunn cells were treated with various concentrations of doxorubicin $(0,0.2,0.4,0.8,1$ and $10 \mu \mathrm{g} / \mathrm{ml})$ for $48 \mathrm{~h}$, and cell viability was measured by Cell Counting Kit- 8 assay. Dose-response curves were generated with GraphPad Prism 8.0 software, and half maximal inhibitory concentrations of doxorubicin were obtained for each group. (B) LM8 and Dunn cells were cultured in the presence of $0.2 \mu \mathrm{g} / \mathrm{ml}$ doxorubicin (with or without CXCR4 knockdown/overexpression) for $48 \mathrm{~h}$, and the expression levels of the apoptosis-related protein cleaved caspase 3, caspase 3 and the drug resistant-related protein P-glycoprotein were then determined by western blotting. The protein bands were quantified and subjected to statistical analysis. (C) LM8 and Dunn cells were cultured with $0.2 \mu \mathrm{g} / \mathrm{ml}$ doxorubicin (with or without CXCR4 knockdown/overexpression) for $48 \mathrm{~h}$, and the apoptosis ratios for each group (percentage of Annexin $\mathrm{V}^{+}$cells) were determined by flow cytometry. ${ }^{*} \mathrm{P}<0.05$, ${ }^{* *} \mathrm{P}<0.01,{ }^{* * *} \mathrm{P}<0.001,{ }^{* * * *} \mathrm{P}<0.0001$. CXCR4, C-X-C motif chemokine receptor 4 .

for $5 \mathrm{~min}$ at each concentration, embedded in epoxy resin for $48 \mathrm{~h}$ at $60^{\circ} \mathrm{C}$ and stained with uranyl acetate. Representative areas were selected for ultrathin sectioning, as detected by transmission electron microscopy (H-9500, Hitachi, Ltd.) (magnification, $\mathrm{x} 12,000$ and $\mathrm{x} 25,000$ ).

Mouse tibia orthotopic tumor model. A total of 32 4-week-old female $\mathrm{C} 3 \mathrm{H}$ mice (16-18 g) were purchased from the Shanghai SLAC Laboratory Animal Co. Ltd., housed under standard conditions with a 12-h light-dark cycle, and fed with pelleted mouse food and water which were provided ad libitum. All the animal procedures were performed in accordance with a protocol approved by the Animal Care and Use Committee of Shanghai Tenth People's Hospital (approval no. SHDSYY-2020-3650). LM8 cells $\left(5 \times 10^{5}\right)$ in $10 \mu$ l PBS were injected into the tibia medullary cavity to establish an orthotopic OS model. Then, 2 weeks after injection of tumor cells, the mice were randomly allocated to four groups: Control ( $\mathrm{n}=8), 5 \mathrm{mg} / \mathrm{kg}$ AMD3100 $(\mathrm{n}=8), 1 \mathrm{mg} / \mathrm{kg}$ doxorubicin $(\mathrm{n}=8)$ and $5 \mathrm{mg} / \mathrm{kg}$ AMD3100 plus $1 \mathrm{mg} / \mathrm{kg}$ doxorubicin $(\mathrm{n}=8)$. Each mouse in the treatment groups received $100 \mu 1$ AMD3100 or doxorubicin by tail vein injection every 2 days. The control mice were injected instead with $100 \mu \mathrm{l}$ PBS. The tumor volume and body weight of each mouse were measured at each injection time point using the formula: Tumor volume $=\left(\right.$ length $\mathrm{x}$ width $\left.{ }^{2}\right) / 2$. Humane endpoints were reached when the xenograft tumor reached $>10 \%$ of the animal's body weight or the tumor diameter was $>20 \mathrm{~mm}$. After eight consecutive injections, the mice that reached study endpoints were anesthetized with $40 \mathrm{mg} / \mathrm{kg}$ pentobarbital injected intraperitoneally, while pentobarbital at a dose of $100 \mathrm{mg} / \mathrm{kg}$ was administered for euthanasia. Death was verified by the cessation of a heartbeat and dilated pupils. Tumors were dissected, weighed and stored in liquid nitrogen or fixed in formalin for immunohistochemical analysis. The maximum tumor diameter and volume observed in this study were $19.2 \mathrm{~mm}$ and $3,819.11 \mathrm{~mm}^{3}$, respectively.

Immunohistochemical staining. Tumor samples were fixed in $4 \%$ paraformaldehyde overnight at room temperature, embedded in paraffin, sliced into $4-\mu \mathrm{m}$ sections, and then deparaffinized 


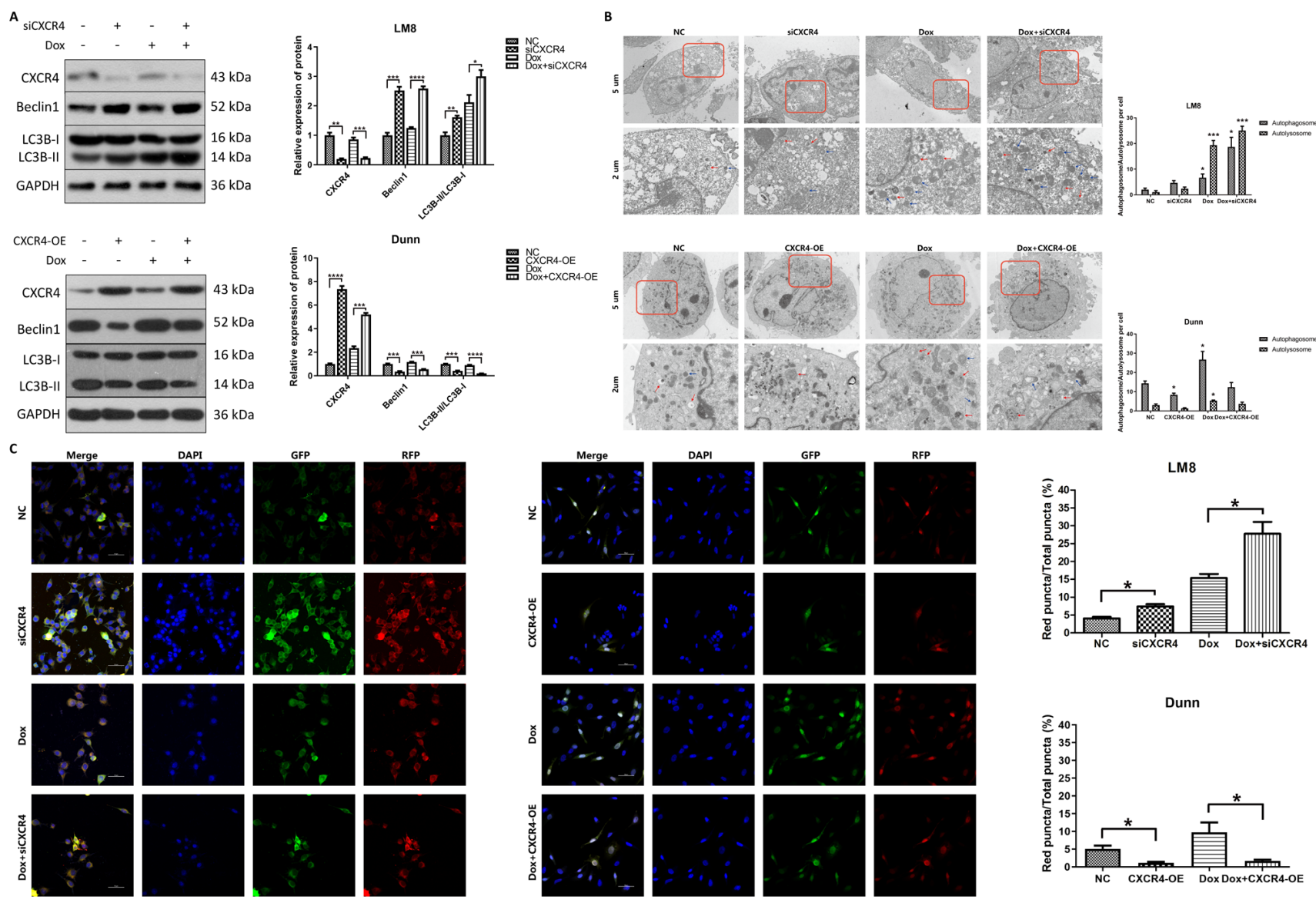

Figure 2. CXCR4 silencing induces autophagy in LM8 cells, while CXCR4 overexpression suppresses autophagy in Dunn cells. (A) The expression levels of CXCR4, and of the autophagy-related proteins beclin 1 and LC3B were determined by western blotting, and the protein bands were quantified and subjected to statistical analysis. The protein bands of GAPDH for CXCR4 silencing and overexpression here are the same as Fig. 1B, as all protein bands in the Fig. 1B and Fig. 2A are from the same blot. (B) Autophagosomes and autolysosomes were detected by transmission electron microscopy in LM8 and Dunn cells after CXCR4 silencing and overexpression respectively. Red arrows indicated autophagosomes, while blue arrows indicated autolysosomes. The number of autophagosomes and autolysosomes was calculated and subjected to statistical analysis. (C) LM8 and Dunn cells were transfected with mRFP-GFP-LC3 adenovirus before treatment. The colocalization of RFP and GFP puncta was examined by confocal microscopy. Yellow puncta represented autophagosomes, while red represented autolysosomes. The percentage of red fluorescence was calculated and analyzed with ImageJ software (National Institutes of Health, version 1.8.0). ${ }^{*} \mathrm{P}<0.05,{ }^{* * *} \mathrm{P}<0.01,{ }^{* * * *} \mathrm{P}<0.001,{ }^{* * * *} \mathrm{P}<0.0001$. CXCR4, C-X-C motif chemokine receptor 4; LC3B, light chain 3B; RFP, red fluorescent protein; GFP, green fluorescent protein.

in xylene, rehydrated with graded alcohol and incubated in $3 \% \mathrm{H}_{2} \mathrm{O}_{2}$ to block endogenous peroxidase activity for $10 \mathrm{~min}$. The slides were then boiled for $30 \mathrm{~min}$ in $10 \mathrm{mM}$ sodium citrate for antigen retrieval, blocked in 5\% BSA (Beyotime Institute of Biotechnology) for $30 \mathrm{~min}$, and incubated with antibodies against CXCR4 (1:400), beclin 1 (1:400), LC3B (1:200) and P-gp (1:200) at $4^{\circ} \mathrm{C}$ overnight. Next, the slides were washed three times with PBS and incubated with horseradish peroxidase-conjugated goat anti-rabbit antibody (1:400; cat. no. ab6721; Abcam) for $30 \mathrm{~min}$ at room temperature. Immunoreactivity was visualized using a 3,3'-diaminobenzidine kit (Beyotime Institute of Biotechnology). The areal density of each image was quantified by Image-Pro Plus 6.0 software (MEDIA CYBERNETICS, USA) for statistical analysis.

Statistical analysis. All data are presented as the mean \pm SD from $\geq 3$ independent experiments. Statistical analysis of differences between two groups was performed using unpaired, two-tailed Student's t-test with GraphPad Prism 8.0 (GraphPad Software, Inc.). $\mathrm{P}<0.05$ was considered to indicate a statistically significant difference.

\section{Results}

CXCR4 silencing sensitizes OS cells to doxorubicin by regulating apoptosis and P-gp. To determine whether CXCR4 affects OS doxorubicin resistance, CXCR4 expression was first downregulated in CXCR4-positive LM8 cells, and CXCR4 expression was upregulated in CXCR4-negative Dunn cells by siRNA and lentiviral transfection, respectively. The differential expression of CXCR4 in the two cells has been described previously (10). It was firstly confirmed that CXCR4 expression was significantly decreased by siCXCR4 in LM8 cells and increased by lentiviral transfection in Dunn cells. LM8 and Dunn cells were then treated with various concentrations of doxorubicin $(0,0.2,0.4,0.8,1$ and $10 \mu \mathrm{g} / \mathrm{ml}$ ) for $48 \mathrm{~h}$, and cell viability was then measured by CCK- 8 assay. The results showed that the $\mathrm{IC}_{50}$ value of CXCR4-knockdown LM8 cells $(0.3879 \mu \mathrm{g} / \mathrm{ml})$ was obviously reduced compared with that of LM8 cells $(0.5891 \mu \mathrm{g} / \mathrm{ml})$. Conversely, the $\mathrm{IC}_{50}$ value of CXCR4-overexpressed Dunn cells $(0.6661 \mu \mathrm{g} / \mathrm{ml})$ was much higher than that of Dunn cells $(0.4581 \mu \mathrm{g} / \mathrm{ml})$ (Fig. 1A). 

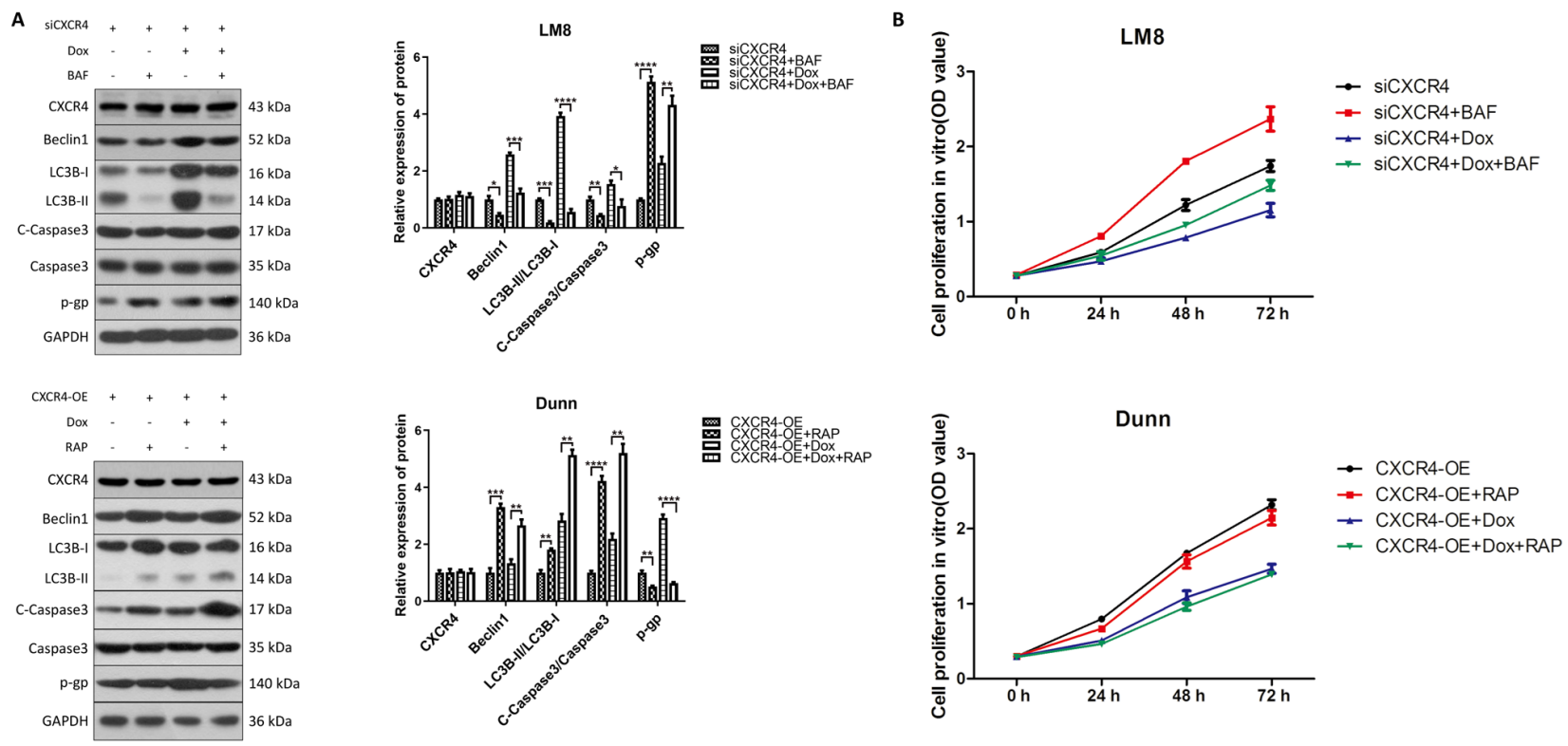

c
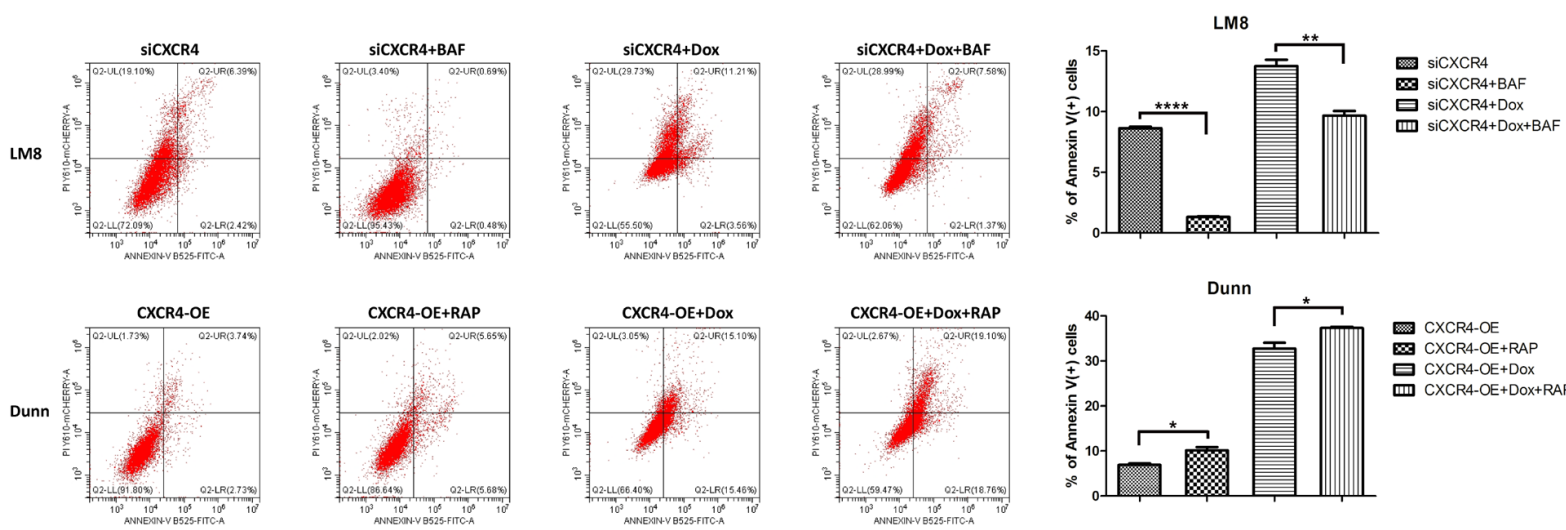

CXCR4-OE

CXCR4-OE+RAP 回 CXCR4-OE+Dox

Figure 3. CXCR4 silencing reverses osteosarcoma doxorubicin resistance by inducing autophagic cell death. (A) LM8 (CXCR4 knockdown) and Dunn (CXCR4 overexpression) cells were pretreated with bafilomycin A1 $(200 \mathrm{nM})$ and rapamycin $(200 \mathrm{nM})$, respectively, for $6 \mathrm{~h}$, and then treated with or without $0.2 \mu \mathrm{g} / \mathrm{ml}$ doxorubicin for $48 \mathrm{~h}$. The expression levels of beclin 1, light chain 3B, cleaved caspase 3, caspase 3 and P-glycoprotein were determined by western blotting, and the protein bands were semi-quantified and subjected to statistical analysis. (B) Cell proliferation in each group was detected by Cell Counting Kit- 8 assay. (C) The apoptosis ratios for each group (percentage of Annexin $\mathrm{V}^{+}$cells) were determined by flow cytometry. ${ }^{*} \mathrm{P}<0.05,{ }^{* *} \mathrm{P}<0.01,{ }^{* * *} \mathrm{P}<0.001,{ }^{* * * *} \mathrm{P}<0.0001$. CXCR4, C-X-C motif chemokine receptor 4.

The expression of the apoptosis-related protein caspase 3 and the multidrug resistance-related P-gp was determined. As revealed by western blot analysis, both CXCR4 knockdown and doxorubicin treatment increased cleaved caspase 3 and reduced P-gp levels in LM8 cells. Furthermore, the highest expression of cleaved caspase 3 and lowest expression of P-gp were found in the doxorubicin combined with CXCR4 knockdown group in LM8 cells. By contrast, CXCR4 overexpression reduced doxorubicin-induced cleaved caspase 3 activation and increased P-gp levels in Dunn cells (Fig. 1B).

To further explore CXCR4-mediated OS doxorubicin resistance, the effect of CXCR4 regulation on apoptosis induced by doxorubicin was investigated in LM8 and Dunn cells by flow cytometry. CXCR4-postive LM8 cells were cultured for $48 \mathrm{~h}$ in the presence of $0.2 \mu \mathrm{g} / \mathrm{ml}$ doxorubicin, CXCR4 silencing or $0.2 \mu \mathrm{g} / \mathrm{ml}$ doxorubicin combined with CXCR4 silencing. CXCR4-negative Dunn cells were cultured for $48 \mathrm{~h}$ in the presence of $0.2 \mu \mathrm{g} / \mathrm{ml}$ doxorubicin, CXCR4 overexpression or $0.2 \mu \mathrm{g} / \mathrm{ml}$ doxorubicin combined with CXCR4 overexpression.
The percentage of apoptotic LM8 cells in the doxorubicin group was $8.12 \pm 0.12$ vs. $10.2 \pm 0.35 \%$ in the doxorubicin combined with siCXCR4 group, which indicated that CXCR4 knockdown increased doxorubicin-induced apoptosis in LM8 cells. By contrast, the percentage of apoptotic Dunn cells in the doxorubicin group was $32.52 \pm 1.14$ vs. $28.19 \pm 0.20 \%$ in the doxorubicin combined with CXCR4-overexpression group, which indicated that CXCR4 overexpression partially reversed doxorubicin-induced apoptosis in Dunn cells (Fig. 1C). These findings suggested that CXCR4 silencing enhanced the sensitivity of LM8 cells to doxorubicin by inducing apoptosis and reducing P-gp levels. By contrast, CXCR4 overexpression reduced the sensitivity of Dunn cells to doxorubicin by inhibiting apoptosis and inducing P-gp expression.

CXCR4 silencing induces autophagy, whereas CXCR4 overexpression inhibits autophagy in OS cells. To investigate the role of autophagy in CXCR4-mediated OS doxorubicin resistance, western blotting was performed to detect the expression 


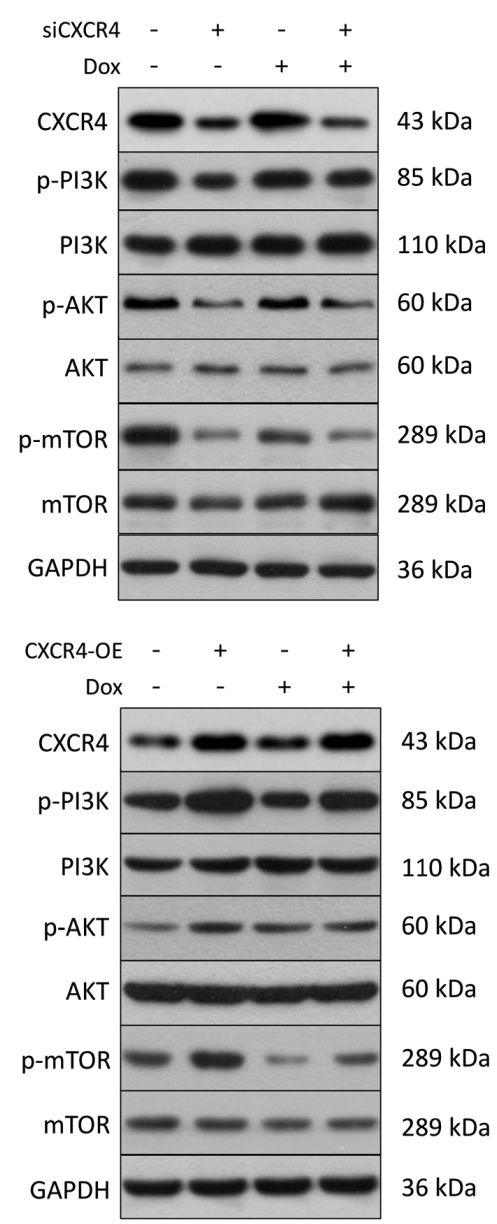

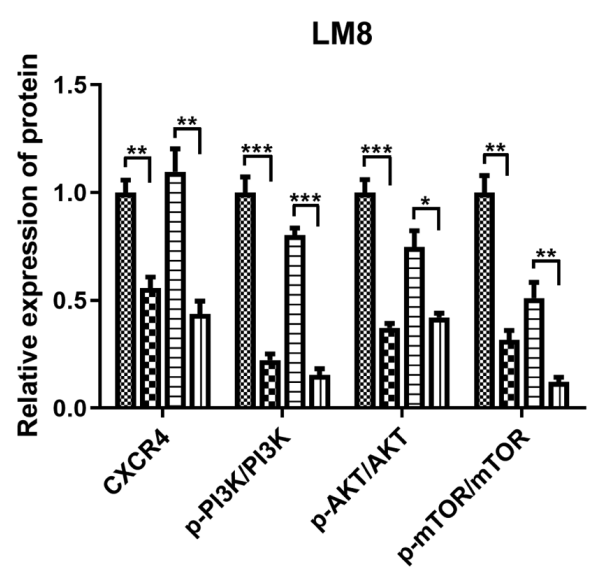
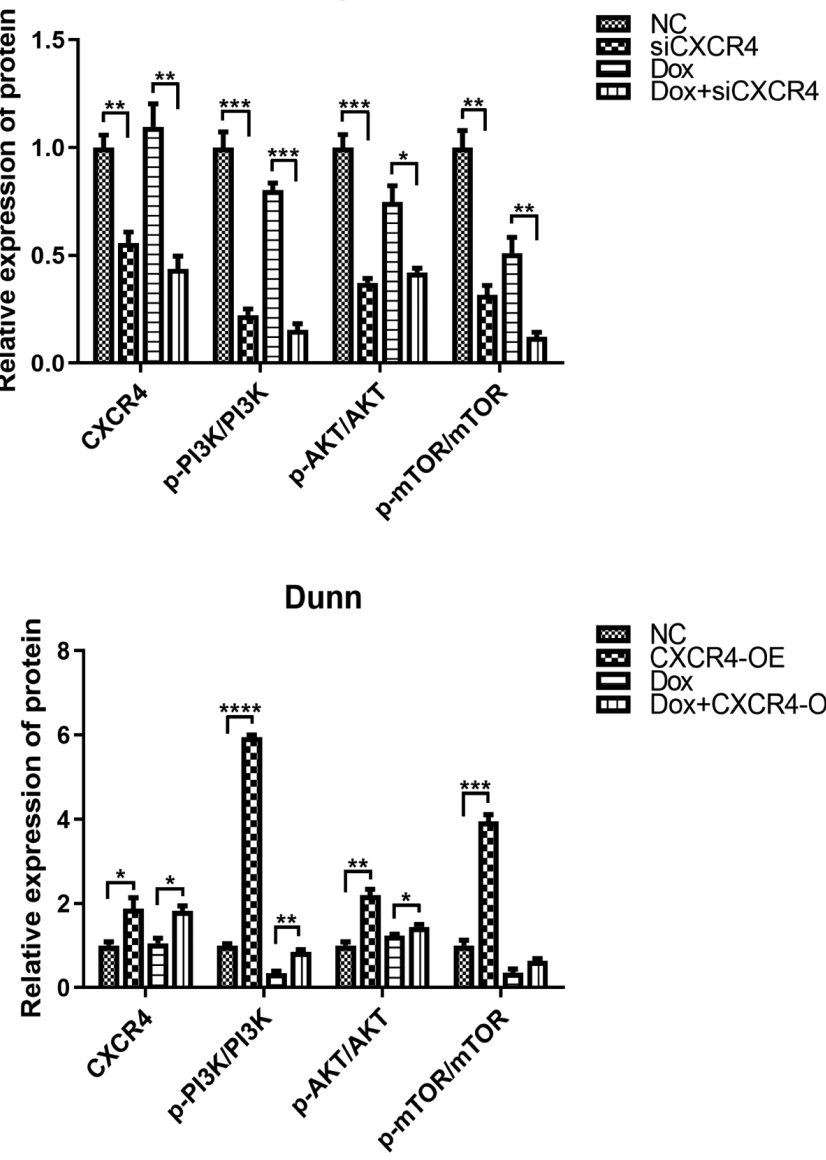

Figure 4. CXCR4 silencing induces autophagic cell death by suppressing the PI3K-AKT-mTOR signaling pathway LM8 and Dunn cells were cultured in the presence of $0.2 \mu \mathrm{g} / \mathrm{ml}$ doxorubicin (with or without CXCR4 knockdown/overexpression) for $48 \mathrm{~h}$, and the expression levels of p-PI3K, PI3K, p-AKT, AKT, p-mTOR and mTOR were determined by western blotting. The protein bands were semi-quantified and subjected to statistical analysis. ${ }^{*} \mathrm{P}<0.05,{ }^{* *} \mathrm{P}<0.01$,

${ }_{* * * *} \mathrm{P}<0.001,{ }^{* * * * *} \mathrm{P}<0.0001$. CXCR4, C-X-C motif chemokine receptor 4; p-, phosphorylated.

levels of the autophagy-related proteins beclin 1 and LC3B after CXCR4 regulation in LM8 and Dunn cells. It is well known that the conversion of LC3B-I to LC3B-II is necessary for autophagosome formation. Therefore, LC3B-II detection has been widely used in autophagy-related research (18). In LM8 cells, both CXCR4 silencing and doxorubicin treatment increased beclin 1 and LC3B-II expression, and the highest expression of beclin 1 and LC3B-II was observed in the doxorubicin combined with CXCR4 silencing group. By contrast, CXCR4 overexpression reduced beclin 1 and LC3B-II expression in Dunn cells compared with that in the control group, and partially reversed the beclin 1 and LC3B-II expression induced by doxorubicin (Fig. 2A).

Transmission electron microscopy, which is considered the golden standard for autophagy detection, was used to observe the ultrastructure of autophagosomes and autolysosomes in OS cells. In LM8 cells, compared with that of the control group, the number of autophagosomes and autolysosomes was obviously increased in both the CXCR4 silencing group and the doxorubicin-treated group, and were further increased in the doxorubicin combined with CXCR4 silencing group. In Dunn cells, the number of autophagosomes and autolysosomes was markedly decreased in the doxorubicin combined with CXCR4 overexpression group compared with that in the doxorubicin group (Fig. 2B).
Considering that autophagy is a dynamic process, mRFP-GFP-LC3 was utilized to observe autophagic flux via confocal microscopy. Specifically, autophagosomes were labeled as yellow puncta, while autolysosomes were labeled as red puncta. In LM8 cells, the percentage of red fluorescence in the CXCR4 silencing group $(7.40 \pm 1.11 \%)$ was higher than that of the control group $(4.07 \pm 0.72 \%)$. The percentage of red fluorescence in the doxorubicin combined with CXCR4 silencing group $(27.77 \pm 5.75 \%)$ was further increased compared with that of the doxorubicin group $(15.40 \pm 1.92 \%)$. In Dunn cells, the percentage of red fluorescence was reduced in the CXCR4 overexpression group $(1.17 \pm 0.51 \%)$ compared with that of the control group $(5.10 \pm 1.60 \%)$. The percentage of red fluorescence was significantly decreased in the doxorubicin combined with CXCR4 overexpression group $(1.67 \pm 0.64 \%)$ compared with that of the doxorubicin group $(9.73 \pm 4.81 \%)$ (Fig. 2C). These results indicated that CXCR4 silencing induced autophagic flux activation in LM8 cells, whereas CXCR4 overexpression suppressed autophagic flux activation in Dunn cells.

CXCR4-mediated autophagic cell death reverses OS doxorubicin resistance. Due to the dual role of autophagy in the regulation of OS chemoresistance, cytoprotective autophagy leads to drug resistance, while autophagic cell death reverses 


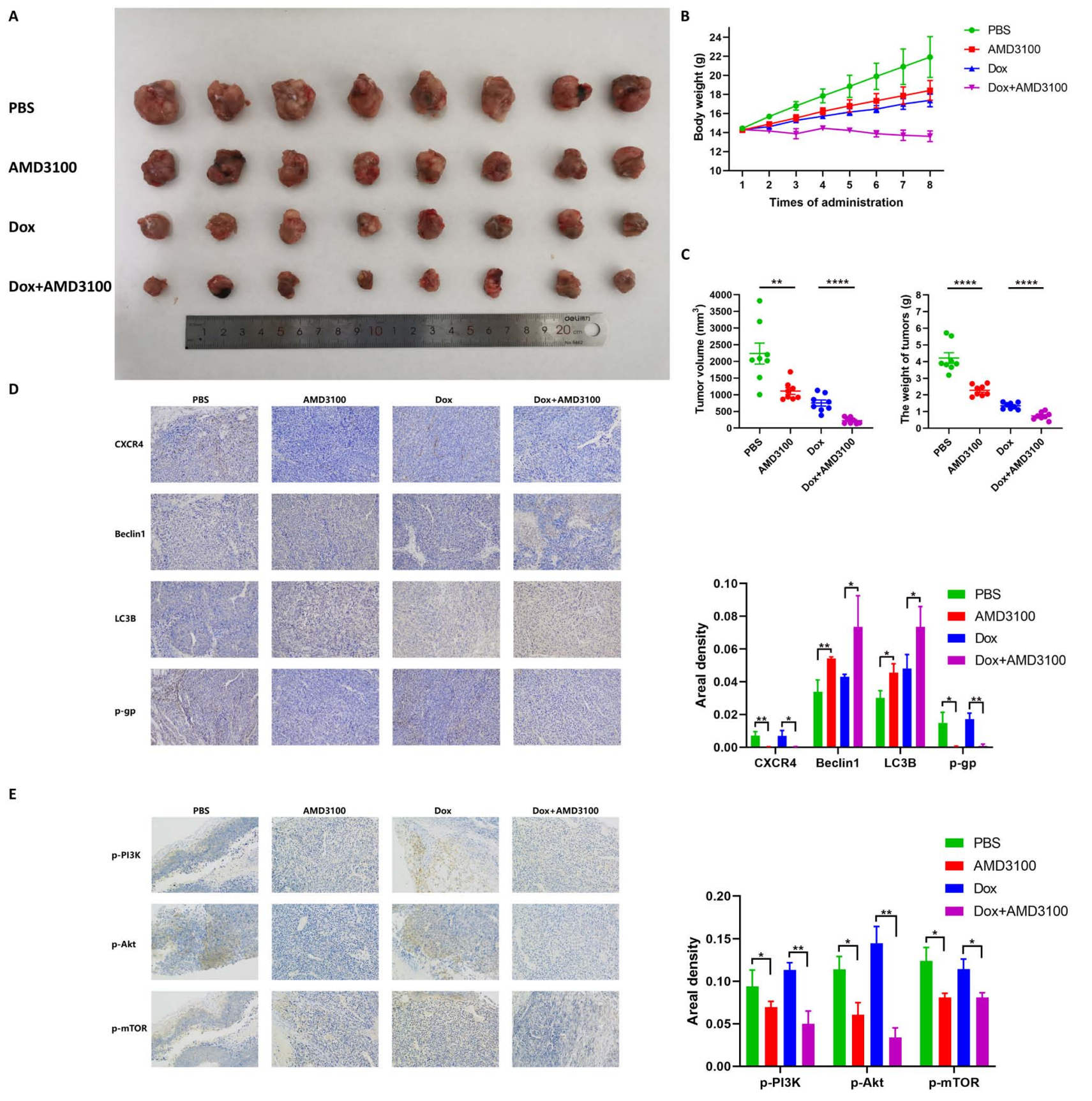

Figure 5. AMD3100 enhances the antitumor effect of doxorubicin in an orthotopic OS mouse model. (A) Macroscopic appearance of OS tumors in the tibia of C3H mice after 8 consecutive injections of PBS, $5 \mathrm{mg} / \mathrm{kg}$ AMD3100, $1 \mathrm{mg} / \mathrm{kg}$ doxorubicin and AMD3100 plus doxorubicin. (B) The body weight of the mice in each group was measured at every injection, and the growth curve was obtained. (C) The volume and weight of the tumors in the four treatment groups were determined. (D) The expression levels of C-X-C motif chemokine receptor 4, beclin 1, light chain 3B and P-glycoprotein in tumor tissues were detected by immunohistochemical staining, and the areal density was quantified and subjected to statistical analysis. (E) The expression of p-PI3K, p-AKT and p-mTOR in tumor tissues was detected by immunohistochemical staining, and the areal density was quantified and subjected to statistical analysis. ${ }^{*} \mathrm{P}<0.05,{ }^{* *} \mathrm{P}<0.01$, ${ }_{* * * * *} \mathrm{P}<0.0001$. OS, osteosarcoma; $\mathrm{p}-$, phosphorylated.

drug resistance (18). To further determine whether CXCR4 silencing increases doxorubicin sensitivity by either inhibiting cytoprotective autophagy or inducing autophagic cell death, the autophagy inhibitor bafilomycin A1 and the autophagy activator rapamycin were used to observe the effect of autophagy on chemoresistance prior to CXCR4 regulation. Western blot analysis revealed that pretreatment with bafilomycin A1 reduced beclin 1, LC3B-II and cleaved caspase 3 levels, and increased P-gp levels in LM8 cells. Conversely, pretreatment with rapamycin increased beclin 1, LC3B-II and cleaved caspase 3 levels, and reduced P-gp levels in Dunn cells (Fig. 3A). Additionally, CCK-8 assay and flow cytometry indicated that pretreatment with bafilomycin A1 promoted cell proliferation in vitro and reversed the apoptosis induced by CXCR4 silencing with or without doxorubicin in LM8 cells. By contrast, rapamycin inhibited cell proliferation in vitro and enhanced doxorubicin-induced apoptosis in Dunn cells (Fig. 3B and C). These results demonstrated that CXCR4 silencing enhances OS doxorubicin sensitivity by inducing autophagic cell death. 


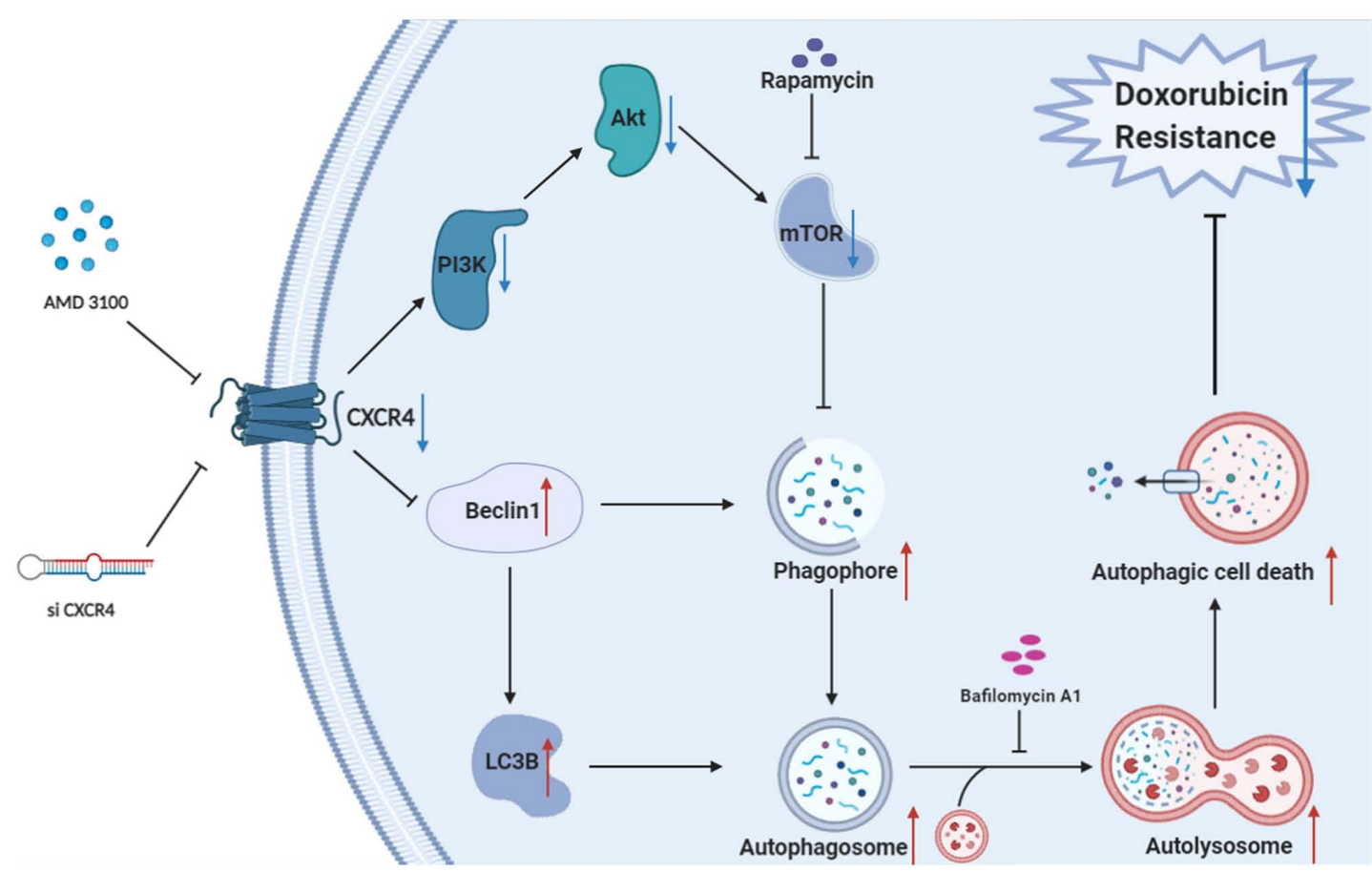

Figure 6. Schematic diagram of the mechanism and function of CXCR4 in OS doxorubicin resistance. CXCR4 blockade by small interfering RNA or AMD3100 enhances the sensitivity of OS to doxorubicin by inducing autophagic cell death via inhibition of the PI3K/AKT/mTOR signaling pathway. OS, osteosarcoma; CXCR4, C-X-C motif chemokine receptor 4.

OS doxorubicin resistance regulated by the CXCR4/autophagy axis is dependent on the PI3K/AKT/mTOR signaling pathway. To further determine whether the CXCR4/autophagy axis modulates OS doxorubicin resistance via the PI3K/AKT/mTOR signaling pathway, one of the most important regulators of autophagy, western blotting was performed to detect the phosphorylation levels of PI3K, AKT and mTOR in LM8 and Dunn cells after doxorubicin treatment and CXCR4 regulation. In LM8 cells, CXCR4 silencing reduced the phosphorylation of PI3K, AKT and mTOR. In Dunn cells, CXCR4 overexpression induced the phosphorylation of PI3K, AKT and mTOR (Fig. 4). These findings indicated that CXCR4 silencing induced autophagic cell death to reverse OS doxorubicin resistance by suppressing the PI3K-AKT-mTOR signaling pathway.

AMD3100 enhances the antitumor effect of doxorubicin in an orthotopic OS mouse model. To investigate whether CXCR4 inhibition could reinforce the cytotoxicity of doxorubicin in vivo, a $\mathrm{C} 3 \mathrm{H}$ mouse orthotopic model was established through intratibial injection of LM8 cells. Mice were randomly allocated to four groups and then treated by tail vein injection with PBS, $5 \mathrm{mg} / \mathrm{kg}$ AMD3100, $1 \mathrm{mg} / \mathrm{kg}$ doxorubicin and AMD3100 plus doxorubicin. After eight consecutive injections, both treatment with AMD3100 and doxorubicin resulted in significant tumor growth inhibition compared to that of the PBS group. Notably, AMD3100 showed a markedly enhanced antitumor effect compared with that of doxorubicin (Fig. 5A). In the dynamic observation of mouse body weight, a different trend was found in the four groups: The body weight in the PBS group increased linearly, while weight gain was delayed in the AMD3100 and doxorubicin groups, and no obvious weight change was observed in the AMD3100 combined with doxorubicin group (Fig. 5B). The results indicated that, compared with that of the PBS group, after eight consecutive administrations of AMD3100, doxorubicin and AMD3100 plus doxorubicin resulted in a notably decreased tumor volume (50.3, 66.3 and $89.9 \%$, respectively), and induced a weight loss of 45.9, 67.9 and $82.4 \%$, respectively. (Fig. 5C). Immunohistochemical staining demonstrated that AMD3100 prominently increased beclin 1 and LC3B expression, and decreased P-gp expression in AMD3100 plus doxorubicin-treated tumor tissues (Fig. 5D). Decreased expression of p-PI3K, p-Akt and p-mTOR was also observed in AMD3100 plus doxorubicin-treated tumor tissues compared with that of other groups (Fig. 5E). These findings suggested that AMD3100 facilitated the antitumor effect of doxorubicin on tumor growth in vivo.

\section{Discussion}

Tumor recurrence, distant metastasis and chemoresistance are three important factors contributing to treatment failure and poor prognosis in OS $(7,19)$. It has already been shown that CXCR4 plays a crucial role in OS survival and metastasis, and targeting CXCR4 is an effective strategy for OS (10-12). However, whether CXCR4 is involved in the regulation of OS chemoresistance and its specific mechanism have not yet been elucidated. The present study first reported that CXCR4 silencing could increase the sensitivity of LM8 cells to doxorubicin by inducing autophagic cell death, while CXCR4 overexpression oppositely increased the chemoresistance of Dunn cells to doxorubicin by inhibiting autophagic cell death. The results further revealed that the negative correlation between CXCR4 and autophagy was dependent on the $\mathrm{PI} 3 \mathrm{~K} / \mathrm{AKT} / \mathrm{mTOR}$ signaling pathway. These findings indicate that CXCR4 abrogation could overcome the chemoresistance of OS cells via autophagic cell death. 
To observe the effect of CXCR4 on OS doxorubicin resistance, the $\mathrm{IC}_{50}$ of doxorubicin in OS LM8 and Dunn cells after CXCR4 regulation was calculated. As shown in our previous study, CXCR4 is highly expressed in LM8 cells and lowly expressed in Dunn cells (10). Therefore, CXCR4 silencing and overexpression were performed in LM8 and Dunn cells, respectively. In LM8 cells, the $\mathrm{IC}_{50}$ value of doxorubicin decreased when CXCR4 expression was inhibited. Conversely, in Dunn cells, the $\mathrm{IC}_{50}$ value of doxorubicin increased when CXCR4 expression was upregulated.

Observation of apoptosis and caspase family protein activation induced by chemotherapy drugs is another method to evaluate chemosensitivity. Since CXCR1 knockdown increased cisplatin-induced apoptosis and caspase 3 activation in Saos2 and Saos2-lung cells, Han et al (20) concluded that CXCR1 knockdown enhanced the sensitivity of OS to cisplatin. Consistent with their findings, the present study found that CXCR4 silencing facilitated doxorubicin-induced apoptosis and caspase 3 activation in LM8 cells, while CXCR4 overexpression partially reversed doxorubicin-induced apoptosis and caspase 3 activation in Dunn cells.

P-gp, also known as MDR1, which is encoded by ATP-binding cassette subfamily B member 1, contributes to chemoresistance in various types of cancer (21). Wang et al (22) demonstrated that raddeanin A restored doxorubicin chemosensitivity in OS drug-resistant U2OSR and KHOSR cells by downregulating MDR1. To further identify whether MDR1/P-gp is involved in CXCR4-mediated doxorubicin resistance, western blotting was utilized to detect changes in P-gp expression after CXCR4 regulation. A positive correlation between CXCR4 and P-gp was found in LM8 and Dunn cell lines. Specifically, both CXCR4 silencing alone and CXCR4 silencing combined with doxorubicin reduced P-gp expression compared with the findings in LM8 cells. On the contrary, both CXCR4 overexpression alone and CXCR4 overexpression combined with doxorubicin increased P-gp expression compared with the findings in Dunn cells. It can be concluded that combination treatment of CXCR4 silencing and doxorubicin exerts an enhanced cytotoxic effect on LM8 cells, while CXCR4 overexpression partially reverses doxorubicin-induced cell death in Dunn cells.

Autophagy is a catabolic process through which cells eliminate and recycle their own damaged proteins and organelles to provide energy. It can be activated under stressful conditions such as hypoxia, starvation and cytotoxicity induced by chemotherapeutic drugs to maintain cell survival (23). Autophagy has long been regarded as a cytoprotective process contributing to OS chemoresistance, and a number of studies have focused on the role of autophagy inhibition in OS chemosensitization. Huang et al (24) found that the chemotherapeutic drugs doxorubicin, cisplatin and methotrexate induced high mobility group box 1 (HMGB1) expression in MG-63, Saos2 and U2OS cells, while downregulation of HMGB1 sensitized OS cells to chemotherapeutic drugs by suppressing the autophagy-related protein beclin 1. Kim et al (25) demonstrated that glial cell line-derived neurotrophic factor receptor $\alpha 1$ promoted OS cisplatin resistance by inducing autophagy. However, further research confirmed that the dual role of autophagy in OS chemoresistance, since cytoprotective autophagy contributes to chemoresistance while autophagic cell death reverses chemoresistance (18).
Recently, attention has been paid to autophagic cell death, which is defined as cell death mediated by autophagy rather than by apoptosis or necrosis (26). An intricate crosstalk between autophagy and apoptosis is probably involved in the mechanism of cell death. Generally, the interaction between autophagy and apoptosis is mostly negative in the sense that autophagy blocks apoptosis induction while apoptosis-related caspase activation suppresses the autophagic process. Notably, the induction of autophagic cell death inversely facilitates apoptosis activation (26). Previous findings revealed that autophagy inhibition could induce apoptosis. Wang et al (27) reported that the antitumor drug combretastatin A-4 (CA-4) could induce cytoprotective autophagy, and combined with the autophagy inhibitor chloroquine, it exerted a synergistic cytotoxic effect on OS cells, since chloroquine further enhanced CA-4-induced apoptosis by elevating the levels of the apoptosis-related proteins poly (ADP-ribose) polymerase (PARP) and caspase 3. Another study found that the microtubule-disrupting agent CYT997 induced both apoptosis and autophagy in OS. Furthermore, pretreatment with the autophagy inhibitor 3-methyladenine (3-MA) enhanced the antitumor effect of CYT997 by increasing cell apoptosis and the levels of the apoptosis-related protein PARP (28). By contrast, honokiol, which is extracted from Magnolia trees, was found to exhibit an antitumor effect on HOS and U2OS cells by inducing both apoptosis and autophagy. In addition, honokiol-induced cell death was more obviously reversed by the autophagy inhibitor 3-MA compared with that induced by the apoptosis inhibitor Z-VAD-FMK, which indicated that honokiol-induced cell death was largely dependent on autophagic cell death (29). Autophagic cell death induced by tanshinone IIA and diallyl disulfide exerted an inhibitory effect on 143B and MG-63 cells, respectively $(30,31)$. Consistent with these findings, the present study observed that CXCR4 silencing combined with or without doxorubicin treatment induced autophagy, as shown by increased expression of beclin 1 and LC3B-II, a larger number of autophagosomes and autolysosomes, and autophagic flux activation. By contrast, CXCR4 overexpression blocked autophagy, as shown by reduced expression of beclin 1 and LC3B-II, a lower number of autophagosomes and autolysosomes, and autophagic flux inactivation. To determine whether CXCR4-mediated autophagy has a pro-survival or pro-death effect, the autophagy inhibitor bafilomycin A1 and the autophagy activator rapamycin were employed to detect the effect of CXCR4-mediated autophagy on cell death induced by doxorubicin. The results revealed that bafilomycin A1 reversed apoptosis induced by CXCR4 silencing with or without doxorubicin in LM8 cells, while rapamycin enhanced doxorubicin-induced apoptosis in Dunn cells, which indicated that the enhanced doxorubicin cytotoxicity caused by CXCR4 silencing was, at least in part, dependent on autophagic cell death.

The mechanisms by which GPCRs regulate autophagy include second messengers such as cAMP and $\mathrm{Ca}^{2+}$, and downstream signal molecules such as ERK1/2 and mTOR complex 1 modulation (32). The role of CXCR4 in the regulation of autophagy is paradoxical, since the positive CXCR4-autophagy loop is involved in drug resistance and metastasis, and CXCR4 induced by reactive oxygen species stimulated autophagy formation, which further contributed to drug resistance in mantle cell lymphoma (14). This result was consistent with those of another study, which found that CXCR4 activation decreased 
the sensitivity of acute myeloid leukemia cells to cytarabine by inducing autophagy (16). In addition, the autophagy inhibitor polymeric chloroquine reduced CXCR4-mediated metastasis in U2OS cells by promoting the internalization of surface CXCR4, which blocked its binding with the extracellular CXCL12 (33). In addition, the negative regulation of CXCR4 in autophagy has also been reported. Coly et al (34) found that CXCR4 activation led to a decrease in the number of autophagosomes in 293 and U87 cells, which indicated that CXCR4 exerted its anti-autophagy effect by activating calpains, which prevented the formation of pre-autophagosomal vesicles. Similar to these results, the present study also observed the anti-autophagy effect of CXCR4 on two OS cell lines. CXCR4 silencing accelerated autophagy activation in LM8 cells by inhibiting the PI3K/AKT/mTOR signaling pathway, which is a well-known negative regulator of autophagy. Inversely, CXCR4 overexpression suppressed autophagy in Dunn cells by activating the $\mathrm{PI} 3 \mathrm{~K} / \mathrm{AKT} / \mathrm{mTOR}$ signaling pathway.

Tumor recurrence, distant metastasis and drug resistance are the three main reasons contributing to OS treatment failure (7). AMD3100, a widely used CXCR4-specific antagonist, only blocks CXCR4 and not any other C-X-C or $\mathrm{C}-\mathrm{C}$ chemokine receptors. Thus, it is commonly applied in cancer research targeting CXCR4 (35). In our previous study, AMD3100 was able to inhibit OS growth and metastasis in vivo (10). However, whether CXCR4 is also involved in OS chemoresistance remains unknown. In the present study, it was found that AMD3100 increased doxorubicin-induced tumor suppression in an OS orthotopic mouse model.

The limitation of this study is the absence of data on human OS cell lines. Given that LM8 and Dunn cells were used in our previous study to demonstrate the role of CXCR4 in the growth and metastasis of OS (10), and our present study focuses on CXCR4-mediated OS chemoresistance, thus we use the LM8 and Dunn cells to perform this study.

In conclusion, the present study shows that CXCR4 blockade enhances the sensitivity of OS to doxorubicin by inducing autophagic cell death by inhibiting the PI3K/AKT/mTOR signaling pathway (Fig. 6). Taken together, these findings elucidate a novel molecular mechanism of CXCR4 in OS doxorubicin resistance regulation. Targeting the CXCR4/autophagy axis may be a promising therapeutic strategy to overcome OS chemotherapy resistance.

\section{Acknowledgements}

We thank Dr Eugenie Kleinerman (MD Anderson Cancer Center, University of Texas, Houston, USA) for kindly donating the murine LM8 and Dunn OS cell lines.

\section{Funding}

This study was supported by the Shanghai Tenth People's Hospital Climbing Talent Program (2021SYPDRC062).

\section{Availability of data and materials}

The datasets used and/or analyzed during the current study are available from the corresponding author on reasonable request.

\section{Authors' contributions}

YXL designed the study and wrote the manuscript. KYL drew the graphical abstract image. JYL and ZFZ performed the in vitro experiments. TYX and DY performed the animal experiments. QMG, LF and GDL collected and analyzed the data. HYY and KYL revised the manuscript critically. All the authors read and approved the final manuscript. YXL, JYL, ZFZ, TYX, DY, QMG, LF, GDL, HYY and KYL confirm the authenticity of all the raw data.

\section{Ethics approval and consent to participate}

The animal procedures were performed in accordance with a protocol approved by the Animal Care and Use Committee of Shanghai Tenth People's Hospital (approval no. SHDSYY-2020-3650).

\section{Patient consent for publication}

Not applicable.

\section{Competing interests}

The authors declare that they have no competing interests.

\section{References}

1. Morrow JJ, Bayles I, Funnell APW, Miller TE, Saiakhova A, Lizardo MM, Bartels CF, Kapteijn MY, Hung S, Mendoza A, et al: Positively selected enhancer elements endow osteosarcoma cells with metastatic competence. Nat Med 24: 176-185, 2018.

2. Siegel RL, Miller KD and Jemal A: Cancer statistics, 2015. CA Cancer J Clin 65: 5-29, 2015.

3. Isakoff MS, Bielack SS, Meltzer P and Gorlick R: Osteosarcoma: Current treatment and a collaborative pathway to success. J Clin Oncol 33: 3029-3035, 2015.

4. Buondonno I, Gazzano E, Tavanti E, Chegaev K, Kopecka J, Fanelli M, Rolando B, Fruttero R, Gasco A, Hattinger C, et al: Endoplasmic reticulum-targeting doxorubicin: A new tool effective against doxorubicin-resistant osteosarcoma. Cell Mol Life Sci 76: 609-625, 2019

5. Gazzano E, Buondonno I, Marengo A, Rolando B, Chegaev K, Kopecka J, Saponara S, Sorge M, Hattinger CM, Gasco A, et al: Hyaluronated liposomes containing $\mathrm{H} 2 \mathrm{~S}$-releasing doxorubicin are effective against P-glycoprotein-positive/doxorubicin-resistant osteosarcoma cells and xenografts. Cancer Lett 456: 29-39, 2019.

6. Xu J, Wang H, Hu Y, Zhang YS, Wen L, Yin F, Wang Z, Zhang Y, Li S, Miao Y, et al: Inhibition of CaMKII $\alpha$ activity enhances antitumor effect of fullerene C60 nanocrystals by suppression of autophagic degradation. Adv Sci (Weinh) 6: 1801233, 2019

7. Chen R, Wang G, Zheng Y, Hua Y and Cai Z: Drug resistance-related microRNAs in osteosarcoma: Translating basic evidence into therapeutic strategies. J Cell Mol Med 23: 2280-2292, 2019.

8. Roundhill EA, Jabri S and Burchill SA: ABCG1 and Pgp identify drug resistant, self-renewing osteosarcoma cells. Cancer Lett 453: 142-157, 2019.

9. Liao YX, Zhou CH, Zeng H, Zuo DQ, Wang ZY, Yin F, Hua YQ and Cai ZD: The role of the CXCL12-CXCR4/CXCR7 axis in the progression and metastasis of bone sarcomas (Review). Int J Mol Med 32: 1239-1246, 2013.

10. Liao YX, Fu ZZ, Zhou CH, Shan LC, Wang ZY, Yin F, Zheng LP, Hua YQ and Cai ZD: AMD3100 reduces CXCR4-mediated survival and metastasis of osteosarcoma by inhibiting JNK and Akt, but not $\mathrm{p} 38$ or Erk1/2, pathways in in vitro and mouse experiments. Oncol Rep 34: 33-42, 2015. 
11. Zhu Y, Tang L, Zhao S, Sun B, Cheng L, Tang Y, Luo Z, Lin Z, Zhu J, Zhu W, et al: CXCR4-mediated osteosarcoma growth and pulmonary metastasis is suppressed by MicroRNA-613. Cancer Sci 109: 2412-2422, 2018.

12. Pollino S, Palmerini E, Dozza B, Bientinesi E, PiccinniLeopardi M, Lucarelli E, Righi A, Benassi MS and Pazzaglia L: CXCR4 in human osteosarcoma malignant progression. The response of osteosarcoma cell lines to the fully human CXCR4 antibody MDX1338. J Bone Oncol 17: 100239, 2019.

13. Li YJ, Dai YL, Zhang WB, Li SJ and Tu CQ: Clinicopathological and prognostic significance of chemokine receptor CXCR4 in patients with bone and soft tissue sarcoma: A meta-analysis. Clin Exp Med 17: 59-69, 2017.

14. Chen Z, Teo AE and McCarty N: ROS-Induced CXCR4 signaling regulates mantle cell lymphoma (MCL) cell survival and drug resistance in the bone marrow microenvironment via autophagy. Clin Cancer Res 22: 187-199, 2016.

15. Dragoj M, Milosevic Z, Bankovic J, Tanic N, Pesic M and Stankovic T: Targeting CXCR4 and FAK reverses doxorubicin resistance and suppresses invasion in non-small cell lung carcinoma. Cell Oncol (Dordr) 40: 47-62, 2017.

16. Hu X, Mei S, Meng W, Xue S, Jiang L, Yang Y, Hui L, Chen Y and Guan MX: CXCR4-mediated signaling regulates autophagy and influences acute myeloid leukemia cell survival and drug resistance. Cancer Lett 425: 1-12, 2018.

17. Liu Y, Liang HM, Lv YQ, Tang SM and Cheng P: Blockade of SDF-1/CXCR4 reduces adhesion-mediated chemoresistance of multiple myeloma cells via interacting with interleukin-6. J Cell Physiol 234: 19702-19714, 2019

18. Liao YX, Yu HY, Lv JY, Cai YR, Liu F, He ZM and He SS Targeting autophagy is a promising therapeutic strategy to overcome chemoresistance and reduce metastasis in osteosarcoma. Int J Oncol 55: 1213-1222, 2019.

19. Lenna S, Bellotti C, Duchi S, Martella E, Columbaro M, Dozza B Ballestri M, Guerrini A, Sotgiu G, Frisoni T, et al: Mesenchymal stromal cells mediated delivery of photoactive nanoparticles inhibits osteosarcoma growth in vitro and in a murine in vivo ectopic model. J Exp Clin Cancer Res 39: 40, 2020.

20. Han XG, Du L, Qiao H, Tu B, Wang YG, Qin A, Dai KR, Fan QM and Tang TT: CXCR1 knockdown improves the sensitivity of osteosarcoma to cisplatin. Cancer Lett 369: 405-415, 2015.

21. Robey RW, Pluchino KM, Hall MD, Fojo AT, Bates SE and Gottesman MM: Revisiting the role of ABC transporters in multidrug-resistant cancer. Nat Rev Cancer 18: 452-464, 2018.

22. Wang Z, Wang C, Zuo D, Zhang T, Yin F, Zhou Z, Wang H, Xu J, Mao M, Wang G, et al: Attenuation of STAT3 phosphorylation promotes apoptosis and chemosensitivity in Human osteosarcoma induced by raddeanin A. Int J Biol Sci 15: 668-679, 2019.

23. Amaravadi RK, Kimmelman AC and Debnath J: Targeting autophagy in cancer: Recent advances and future directions. Cancer Discov 9: 1167-1181, 2019.
24. Huang J, Liu K, Yu Y, Xie M, Kang R, Vernon P, Cao L, Tang D and Ni J: Targeting HMGB1-mediated autophagy as a novel therapeutic strategy for osteosarcoma. Autophagy 8: 275-277, 2012.

25. Kim M, Jung JY, Choi S, Lee H, Morales LD, Koh JT, Kim SH, Choi YD, Choi C, Slaga TJ, et al: GFRA1 promotes cisplatin-induced chemoresistance in osteosarcoma by inducing autophagy. Autophagy 13: 149-168, 2017.

26. Marino G, Niso-Santano M, Baehrecke EH and Kroemer G: Self-consumption: The interplay of autophagy and apoptosis. Nat Rev Mol Cell Biol 15: 81-94, 2014.

27. Wang H, Li W, Xu J, Zhang T, Zuo D, Zhou Z, Lin B, Wang G, Wang Z, Sun W, et al: NDRG1 inhibition sensitizes osteosarcoma cells to combretastatin A-4 through targeting autophagy. Cell Death Dis 8: e3048, 2017.

28. Wang Z, Yin F, Xu J, Zhang T, Wang G, Mao M, Wang Z, Sun W, Han J, Yang M, et al: CYT997(Lexibulin) induces apoptosis and autophagy through the activation of mutually reinforced ER stress and ROS in osteosarcoma. J Exp Clin Cancer Res 38: 44, 2019.

29. Huang K, Chen Y, Zhang R, Wu Y, Ma Y, Fang X and Shen S: Honokiol induces apoptosis and autophagy via the ROS/ERK1/2 signaling pathway in human osteosarcoma cells in vitro and in vivo. Cell Death Dis 9: 157, 2018.

30. Yen JH, Huang ST, Huang HS, Fong YC, Wu YY, Chiang JH and Su YC: HGK-sestrin 2 signaling-mediated autophagy contributes to antitumor efficacy of Tanshinone IIA in human osteosarcoma cells. Cell Death Dis 9: 1003, 2018.

31. Yue Z, Guan X, Chao R, Huang C, Li D, Yang P, Liu S, Hasegawa T, Guo J and Li M: Diallyl disulfide induces apoptosis and autophagy in Human osteosarcoma MG-63 cells through the PI3K/Akt/mTOR pathway. Molecules 24: 2665, 2019.

32. Wauson EM, Dbouk HA, Ghosh AB and Cobb MH: G protein-coupled receptors and the regulation of autophagy. Trends Endocrinol Metab 25: 274-282, 2014.

33. Yu F, Li J, Xie Y, Sleightholm RL and Oupicky D: Polymeric chloroquine as an inhibitor of cancer cell migration and experimental lung metastasis. J Control Release 244: 347-356, 2016

34. Coly PM, Perzo N, Le Joncour V, Lecointre C, Schouft MT, Desrues L, Tonon MC, Wurtz O, Gandolfo P, Castel $\mathrm{H}$ and Morin F: Chemotactic G protein-coupled receptors control cell migration by repressing autophagosome biogenesis. Autophagy 12: 2344-2362, 2016.

35. Wang J, Tannous BA, Poznansky MC and Chen H: CXCR4 antagonist AMD3100 (plerixafor): From an impurity to a therapeutic agent. Pharmacol Res 159: 105010, 2020.

This work is licensed under a Creative Commons Attribution-NonCommercial-NoDerivatives 4.0 International (CC BY-NC-ND 4.0) License. 